\title{
Lesões pulmonares provocadas pela nicotina por via subcutânea em ratos $^{1}$
}

\author{
Aldo da Cunha Medeiros ${ }^{2}$ \\ Keyla Ferreira Borges da Rocha ${ }^{3}$ \\ Antônio Medeiros Dantas Filho ${ }^{4}$ \\ Tertuliano Aires Neto ${ }^{4}$ \\ Ítalo Medeiros de Azevêdo ${ }^{5}$
}

\begin{abstract}
Medeiros AC, Lima PF, Dantas Filho AM, Aires Neto T. Lesões pulmonares provocadas pela nicotina por via subcutânea em ratos. Acta Cir Bras [online] 2003 vol 18 suppl 1. Disponível em www.scielo.br/acb.
\end{abstract}

RESUMO: Objetivo: Estudo com o objetivo de observar a influência da nicotina, aplicada pela via subcutânea, em pulmões de ratos. Métodos: Foram utilizados 20 ratos Wistar pesando $235 \pm 35 \mathrm{~g}$, separados aleatoriamente em 2 grupos iguais. O grupo I $(n=10)$ recebeu nicotina na dose de $2 \mathrm{mg} /$ $\mathrm{Kg} /$ dia pela via subcutânea durante 20 dias e o grupo II $(n=10)$ recebeu placebo pela mesma via de administração. Resultados: Os resultados mostraram que no grupo I ocorreu broncopneumonia em $3(30 \%)$ ratos, leucocitose alveolar em $10(100 \%)$ e leucocitose septal em 7 (70\%). Atelectasia foi encontrada em 2 (20\%). Transformados em escores, os dados totalizaram 52 pontos. Os escores das alterações observadas nos pulmões do grupo II atingiram 11 pontos $(p<0,05)$. Conclusão: Os dados permitiram concluir que o uso da nicotina por via subcutânea contribuiu para o aparecimento de lesões pulmonares em ratos, em número e intensidade significativamente maiores do que nos animais considerados controles.

DESCRITORES: Nicotina. Via subcutânea. Pulmões.

\section{INTRODUÇÃO}

Entre as toxinas do cigarro, a nicotina tem sido a melhor estudada ${ }^{1}$, estando presente em doses de 1,5 a $8 \mathrm{mg}$ por cigarro, correspondendo de 15 a $20 \%$ da composição do tabaco ${ }^{2}$. Aproximadamente $95 \%$ da nicotina contida no fumo é absorvida desde a mucosa da boca até os alvéolos, ocorrendo maior absorção na cavidade oral. A nicotina de reação básica é mais encontrada no charuto e cachimbo e tem maior absorção alveolar, enquanto a ácida existe em maior intensidade no cigarro industrializado ${ }^{2}$. Age como irritante para as vias aéreas, tanto se inalada quanto se administrada por outras vias, desencadeando o mecanismo da tosse através do estímulo dos receptores de irritação e de pressão e de fibras $\mathrm{C}$ broncopulmonares, servindo os nervos vagais presumivelmente como via aferente ${ }^{3}$.

A presença de vários neuropeptídeos ( substância $\mathrm{P}$, peptídeo relacionado ao gene da calcitonina e neuroquinina A) nas terminações aferentes das fibras $\mathrm{C}$ broncopulmonares já foi claramente demonstrada ${ }^{4}$. Os potentes efeitos dos mesmos na musculatura lisa vascular e brônquica, permeabilidade vascular, secreção de glândulas mucosas, neurotransmissão colinérgica, e função de células de defesa no tracto respiratório estão bem documentados ${ }^{5}$.

$\mathrm{O}$ efeito broncoconstrictor da nicotina aumenta a resistência bronquial à ventilação pulmonar, influi diminuindo o consumo de $\mathrm{O}_{2}$ e a atividade da enzima

1. Trabalho realizado no Núcleo de Cirurgia Experimental Prof. Travassos Sarinho - UFRN. Apoiado pelo CNPq.

2. Doutor em Cirurgia; Coordenador da Disciplina de Técnica Operatória-UFRN; Chefe do Núcleo de Cirurgia Experimental; Pesquisador nível I do CNPq

3. Prof. Mestre do Departamento de Patologia da UFRN.

4. Prof. de Técnica Operatória - UFRN, alunos do Programa de Pós-graduação

5. Aluno do Departamento de Estatística-UFRN. 
adenosina-trifosfatase dos macrófagos alveolares, prejudicando a função fagocitária destes, o que predispõe o indivíduo a infecções ${ }^{6}$. Ratas expostas ao fumo do tabaco foram examinadas por microscopia óptica e eletrônica, tendo sido observadas alterações de todo o trato respiratório, quais sejam, perda ciliar, mudanças importantes na estrutura ciliar (como assimetria e alongamento), infiltrado inflamatório nasal, traqueal e pulmonar, aumento na quantidade de células caliciformes e abundante produção de muco ${ }^{7}$. Os dados disponíveis corroboram com fato de que a nicotina desempenha importante papel no desenvolvimento de doenças cardiovasculares e pulmonares ${ }^{5}$.

Muitos indivíduos, durante o tratamento da dependência do tabaco, utilizam a nicotina transdérmica como uma das alternativas. Como há poucos estudos a respeito da repercussão pulmonar da droga administrada por outras vias que não a respiratória, o presente trabalho procurou estudar possíveis alterações histopatológicas pulmonares em ratos submetidos à aplicação de nicotina à distância, no subcutâneo da região dorsal.

\section{MÉTODOS}

Foram utilizados 20 ratos adultos jovens da raça Wistar com peso de $235 \pm 35 \mathrm{~g}$, provenientes do biotério do Núcleo de Cirurgia Experimental da Universidade Federal do Rio Grande do Norte. Mantidos em gaiolas individuais com água e alimento ad libitum e submetidos a ciclo claro-escuro de 12 horas, foram divididos aleatoriamente em dois grupos I $(n=10)$ e II $(n=10)$ e operados em condições de assepsia após anestesia com pentobarbital sódico na dose de $20 \mathrm{mg} / \mathrm{Kg}$ de peso por via intraperitoneal.

Os animais foram tratados com nicotina $\left(\right.$ Nicotinell $\left.^{\circledR}\right)$ implantada na região dorsal por via subcutânea, na dose de $2 \mathrm{mg} / \mathrm{Kg}$ dia, sendo os discos contendo nicotina trocados em dias alternados. Todos os animais do grupo I (experimental) receberam a dose de nicotina pré-estabelecida durante 20 dias. No grupo II (controle) foram utilizados discos de celulose sem nicotina através da mesma via e prazo de utilização do grupo experimental.

Após completado o período de uso da droga, os animais de ambos os grupos foram mortos com superdose de anestésico e realizada biópsia de ambos os pulmões. Para o exame histopatológico, as peças foram fixadas em formol a $10 \%$ por 48 horas e a seguir processadas através de coloração com hematoxilina-eosina, sendo analisadas através de microscopia óptica. As lâminas foram examinadas com o objetivo de quantificar os achados histopatológicos, conferindo-se intensidade de 0 a 4 para as alterações verificadas. Os achados histopatológicos e suas respectivas intensidades foram multiplicados pelo número de animais que os apresentavam, os resultados foram somados e transformados no escore de cada grupo.

Todos os procedimentos com os animais foram realizados de acordo com as normas estabelecidas pela Declaração de Helsinki.

Os dados obtidos foram analisados através do teste Qui-quadrado considerando-se a diferença significante quando $p<0,05$.

\section{RESULTADOS}

O exame histopatológico das lâminas demonstrou as alterações que podem ser observadas na tabela 1 . No grupo I ocorreu broncopneumonia grau 2 em três ratos $(30 \%)$.

Tabela 1. Mostra a distribuição dos escores histológicos nas várias alterações observadas nos grupos I e II.

\begin{tabular}{|c|c|c|c|c|c|c|c|c|}
\hline \multirow{2}{*}{$\begin{array}{l}\text { Alterações observadas } \\
\text { INTENSIDADES } \\
\end{array}$} & \multicolumn{4}{|c|}{ GRUPO I } & \multicolumn{4}{|c|}{ GRUPO II } \\
\hline & $0+$ & $1+$ & $2+$ & $3+$ & $0+$ & $1+$ & $2+$ & $3+$ \\
\hline Broncopneumonia & & & 3 & & & 2 & & \\
\hline Pneumonia & & 4 & 3 & & & & & \\
\hline Leucocitose alveolar & & 5 & 3 & 2 & & 2 & & \\
\hline Leucocitose septal & & 2 & 5 & & & & & \\
\hline Atelectasia & & 2 & & & & 2 & & \\
\hline Hemorragia alveolar & & 3 & 1 & & & 5 & & \\
\hline TOTAL DOS ESCORES & 0 & 16 & 30 & 6 & 0 & 11 & 0 & 0 \\
\hline ESCORES POR GRUPO & & & $=52$ & & & Esc & & \\
\hline
\end{tabular}


As intensidades de 0 a $3+$ foram multiplicadas pelo número de ratos que apresentaram cada alteração, resultando no escore total para cada grupo. A diferença dos escores entre os dois grupos foi significante $(p<0,05)$.

No grupo I pneumonia foi encontrada em 7 (70\%) e considerada de grau $1 \mathrm{em}$ quatro animais e de grau 2 em três deles. Leucocitose alveolar foi encontrada em todos os animais deste grupo. A intensidade 1 foi observada em cinco ratos e intensidade 2 em três animais. Em sete ratos (70\%) ocorreu leucocitose septal, sendo que em dois com intensidade $1 \mathrm{e} \mathrm{em}$ cinco com intensidade 2. Atelectasia de intensidade 1 ocorreu em dois ratos e observou-se hemorragia alveolar em quatro indivíduos deste grupo (40\%). A hemorragia foi considerada de intensidade 1 em três ratos e de intensidade 2 em um deles.

No grupo II foram encontradas alterações leves (intensidade 1) distribuídas do seguinte modo: broncopneumonia em dois animais, leucocitose alveolar em dois, atelectasia em dois e hemorragia alveolar em cinco ratos. $\mathrm{O}$ escore desse grupo atingiu 11 pontos.

Quando da realização da soma do número de alterações pulmonares observadas e multiplicadas pelas respectivas intensidades (tabela 1), encontraram-se escores com diferenças significantes entre os dois grupos $(p<0,05)$.

\section{DISCUSSÃO}

No presente estudo, verificou-se que a nicotina, mesmo utilizada por via subcutânea, atingiu os pulmões à distância, provocando lesões nos brônquios, bronquíolos, septos alveolares e alvéolos. Tem sido observado que a nicotina, tanto inalada quanto administrada no homem por outras vias, provocam irritação das vias aéreas, como pôde ser demonstrado através da análise dos dados aqui disponíveis ${ }^{3}$.

A nicotina é rapidamente transportada ao cérebro" atingindo-o em aproximadamente 7 segundos. Por ser quimicamente semelhante à acetilcolina, liga-se aos receptores nicotínicos no cérebro. Quando presente em baixas concentrações estimula-os e, quando em altas concentrações, inibe-os ${ }^{4}$. Age nos receptores nicotíni$\cos$ da junção neuromuscular, medula adrenal e gânglios autônomos, na ativação de diversas vias neuro-humorais do sistema nervoso central, levando à liberação de acetilcolina, noradrenalina, dopamina, serotonina, vasopressina e $\mathrm{ACTH}^{4}$. Além dessas ações, a nicotina poderá agir como um promotor oncogênico e ativador de carcinógenos. Pesquisas na área sugerem que, em roedores, carcinógenos derivados da nicotina como o NNN e o NNK são potentes agentes indutores de câncer pulmonar $^{10}$.
Observou-se também que a administração de nicotina causa alterações nos glicosaminoglicanos (GAG) tissulares semelhantes àquelas encontradas na exposição de ratos à fumaça do cigarro. Verificou-se aumento de muitos dos GAG nos pulmões, da mesma forma que está aumentada a concentração de GAG no adenocarcinoma pulmonar, podendo estar a nicotina aí novamente relacionada à elevada incidência de neoplasia pulmonar em fumantes ${ }^{10,11}$. Foi demonstrada diminuição de muitas das frações de GAG na aorta, fígado e coração, cuja associação com o acúmulo de lipídeos na aorta, ainda relacionada à nicotina, pode responsabilizar o tabagismo como fator de risco para a doença aterosclerótica ${ }^{11}$.

Estudos realizados em ratas submetidas a inalação de nicotina na sua forma pura não mostraram efeitos nocivos, porém observou-se redução no peso quando comparados com grupos controle. Efeito similar no peso foi observado em estudos onde a nicotina foi administrada através de dispositivos osmóticos colocados no tecido subcutâneo ${ }^{11}$.

$\mathrm{O}$ uso da nicotina transdérmica em 41 grupos que totalizaram 5.501 pacientes resultou em efeitos adversos leves, que incluíram sintomas respiratórios, náuseas, vômitos e irritação da pele ${ }^{12}$. Em alguns casos relatados de tentativa de suicídio com superdose de nicotina transdérmica, ocorreu insuficiência respiratória em 44,4\% dos pacientes, além de complicações cardiovasculares em $66,6 \%$ dos $\operatorname{casos}^{13}$. No estudo aqui descrito ocorreram alterações histopatológicas significativas na maioria dos ratos estudados, certamente pelo fato de que eles não tiveram contato crônico prévio com a nicotina. Estudo realizado em 80 fumantes em programa para abandono do vício do tabaco revelou que o uso diário da nicotina transdérmica resultou em 31 não fumantes após 26 semanas de tratamento. A nicotina transdérmica nesse estudo mostrou-se bem tolerada, com alguns efeitos colaterais como eritema cutâneo e insônia. Repercussões respiratórias adicionais não foram relatadas, certamente porque lesões pulmonares já existiam em decorrência do uso prolongado do tabaco por inalação ${ }^{14}$. A propósito, 80 voluntários submetidos a inalação profunda de fumaça de cigarro e estudados através de tomografia computadorizada de alta resolução, desenvolveram doença pulmonar obstrutiva crônica em percentagem significativa, enquanto não fumantes apresentaram resultados normais ${ }^{15}$.

Campos et $\mathrm{al}^{17}$ estudando os efeitos da nicotina por via subcutânea, em retalhos de pele de ratos, concluíram que a droga tem efeito prejudicial ao retalho cutâneo, aumentando a área de necrose quando utilizou-a no préoperatório. A continuidade do seu uso no pós-operatório contribuiu para aumentar a necrose dos retalhos. O uso 
subcutâneo da nicotina foi testado em ratas grávidas, com o objetivo de quantificar os efeitos durante a gestação e lactação, no desenvolvimento neonatal dos pulmões dos ratos recém-nascidos. Os resultados mostraram diminuição na contagem dos alvéolos, aumento no índice destrutivo, aumento no número de alvéolos anormais e aumento na celularidade septal dos pulmões dos ratos recém-nascidos ${ }^{16}$. Apesar desse estudo apresentar o enfoque do efeito da nicotina por via subcutânea, desde a mãe até os pulmões dos recém-nascidos, trata-se da constatação de ação da droga à distância, na mesma linha de raciocínio do presente trabalho.

Conclusão: os dados obtidos permitem concluir que a nicotina aplicada por via subcutânea contribuiu para o surgimento de lesões significativas nos pulmões de ratos.

\section{REFERÊNCIAS}

1. Kart M D. Cigarette smoking as a risk factor for epidemic H1H1 influenza in young men. New Eng J Med., 1992; 307: 1042-1046.

2. Jonsson K, Jensen J A, Goodson W H. Tissue oxigenation, anemia and perfusion in relation to wound healing in surgical patients. Ann Surg 1991; 214 (5) : 605 - 13.

3. Lee L.Y, Gerhardstein D C, Wang A L, Burki NK. Nicotine is responsible for airway irritation evoked by cigarette smoke inhalation in men. J Appl Physiol 1993; 75: 1955-1961.

4. Benowitz N. Pharmacologic aspects of cigarette Smoking and Nicotine Addiction. New Engl J Med 1988;319:1330-1334.

5. Schuen JN, Bamford OS, Carroll JL. The cardiorespiratory response to anoxia: normal development and the effect of nicotine. Resp Physiol 1997; 109: 231-239.
6. Hemingfield JE, Nemeth-Coslett R. Nicotine dependence Interface between tobaco and tobaco-related disease. Chest (Feb Suppl) 1988; 37S - 55S.

7. Rowell PP, Hurst E E, Marlowe C, Bennet B D. Oral administration of nicotine: its uptake and distribution after chronic administration to mice. J Pharmacol Methodol 1983; 9: $249-261$

8. Netscher DT, Clamon J. Smoking: adverse effects on outcomes for plastic surgical patients. Plast Surg Nurs 1994; 14(4) : 205 -10 .

9. Benowitz N L. Smoking and nicotine addiction. Surg Cl N Am 1992; 72: 417 - 439

10. Minna JD. The molecular biology of lung cancer pathogenesis. Chest 1993; 103: 449-456.

11. Kurup PA, Vijayammal PL, Latha MS. Effect of nicotine on glycosaminoglycan metabolism in rats. Indian J Exp Biol 1992; 30:219-223.

12. Greenland S, Satterfield MH, Lanes SF. A meta-analysis to assess the incidence of adverse effects associated with the transdermal nicotine patch. Drug Saf 1998; 18: 297-308.

13. Woolf A, Burkhart K, Caraccio T, Litovitz T. Self-poisoning among adults using multiple transdermal nicotine patches. J Toxicol Clin Toxicol 1996; 34: 691-698.

14. Martin PD, Robinson GM. The safety, tolerability and efficacy of transdermal nicotine. N Z Med J 1995; 108: 6-8.

15. Clark KD, Wardrobe-Wong N, Elliott JJ. Cigarette smoke inhalation and lung damage in smoking volunteers. Eur Resp J 1998; 12: 395-399.

16. Maritz GS, van Wyk G. Influence of maternal nicotine exposure on neonatal rat lung structure: protective effect of ascorbic acid. Comp Biochem Phys C Pharmacol Toxicol Endocrinol 1997; 117: 159-165

17. Campos H, Ferreira LM, Santos WC, Araújo MCM. Efeitos da nicotina nos retalhos cutâneos em ratos. Acta Cir Bras 2001; 17:206-210.

Medeiros AC, Pignataro F, Dantas Filho AM, Aires Neto T. Influence of subcutaneous nicotine in the lungs of rats. Acta Cir Bras [online] 2003 vol 18 suppl 1. Available in www.scielo.br/acb.

ABSTRACT: Objective: The aims of this study were to determine and quantify the influence of nicotine, applied subcutaneously, in the lungs of rats. Methods: Twenty Wistar rats weighing $235 \pm 35 \mathrm{~g}$ were randomly separated in two groups. The group I $(\mathrm{n}=10)$ received nicotine $(2 \mathrm{mg} / \mathrm{Kg}$ body mass/day) during 20 days and the group II $(\mathrm{n}=10)$ received placebo subcutaneously. Results: The results illustrate that in the group I resulted bronchopneumonia in $3(30 \%)$ rats, alveolar leucocitosis in $10(100 \%)$, septal leucocitosis in $7(70 \%)$ and atelectasia was found in $2(20 \%)$. Transformed in scores, the data totalized 52 points. The scores of the lesions observed in the lungs of group II rats reached 11 points $(p<0,05)$. Conclusion: These findings indicate and conclude that the use of nicotine subcutaneously can be implicated in significant lung lesions in rats, when compared with controls.

KEY WORDS: Nicotine. Subcutaneous use. Lungs.

Correspondência:

Aldo da Cunha Medeiros

Av. Miguel Alcides Araújo 1889

59078-270 Natal, RN. 